\title{
Impact of radioactivity on the environment: Problems, state of current knowledge and approaches for identification of radioprotection criteria
}

\author{
F. BRÉCHIGNAC
}

(Manuscript received 12 September 2001, accepted 6 November 2001)

ABSTRACT There is currently a revitalized concern about the potential impact of ionizing radiation on the environment that calls for the construction of a system ensuring an adequate radioprotection of the non-human biota and their associated biotopes. This paper first sets the context of the problem both, with respect to the general philosophy of environmental protection as a whole, but also with respect to the consideration of the environment achieved so far in the purpose of human radioprotection. The current accumulated knowledge on the effects of ionizing radiation to biota (fauna and flora) is then briefly reviewed, encompassing effects at individual and community/ecosystem level, situations of acute and chronic exposure to high and low doses, finally leading to the identification of the most critical gaps in scientific knowledge: effects of mixed low dose rates in chronic exposure to communities and ecosystems. The most significant current international efforts towards the identification of environmental radioprotection criteria and standards are finally presented along with some relevant national examples.

RÉSUMÉ Impact de la radioactivité sur l'environnement : problématique, état des connaissances et approches vers l'identification de critères de radioprotection.

On assiste actuellement à une revitalisation de la question de l'impact des radiations ionisantes sur l'environnement qui appelle la construction d'un système capable d'assurer une radioprotection adéquate des êtres vivants non-humains et des biotopes qui leurs sont associés. Cette publication situe d'abord le problème dans le cadre général de la philosophie actuelle qui prévaut en matière de protection de l'environnement en général, et aussi dans le contexte dans lequel ce dernier a été pris en considération jusqu'à aujourd'hui par la radioprotection de l'homme. L'état actuel de la connaissance acquise à propos des effets des radiations ionisantes sur les êtres vivants animaux et végétaux est ensuite brièvement rappelé, de l'échelle des individus à celle des communautés et des écosystèmes, des expositions aiguës aux expositions chroniques, aux fortes et aux faibles doses, pour finalement déboucher sur l'identification des lacunes les plus critiques : les effets de combinaisons de faibles doses en situation d'exposition chronique sur les communautés vivantes et les écosystèmes. Sont ensuite présentés les efforts internationaux les plus significatifs entrepris dans le but d'identifier des critères et des méthodes standards pour la radioprotection de l'environnement, ainsi que quelques exemples nationaux pertinents.

\footnotetext{
'Institut de protection et de sûreté nucléaire, Département de protection de l'environnement, Service d'érudes et de recherches radió́cologiques de laboratoire, Centre d'études de Cadarache, BP 1, 13108 Saint-Paul-lez-Durance, France.
} 


\section{Introduction}

\subsection{Context}

In the modern world, environmental protection currently forms a preoccupation that is overwhelming several fields, from resource management to preservation/restoration of biotopes and biocenoses with respect to miscellaneous anthropic stresses, radiological protection included. The latest international conferences on the environment (Rio and Kyoto) have brought two new concepts to the forefront, which are now consensual. The sustainable development concept acknowledges that human activities must "respect" the biotopes and biocenoses that make up the biosphere, as they condition the support of all life in the present and future, on our planet. The precautionary principle endeavours to overcome insufficient scientific knowledge, in particular where long-term effects created by human activities are concerned, by means of an optimised risk approach.

The developments of the nuclear industry have been initiated by man, who is therefore primarily preoccupied, and quite rightly so, by his own radiological protection. The philosophy, ideas and practical application of this radioprotection have been successfully set up, through the construction of an international consensus, by the International Commission on Radiological Protection. In this context where man is the target to be protected, the wider environment has only been taken into account in a restrictive manner, that is to say in as much that it provides a direct vector for the exposure of man. As an answer to the growing preoccupation with environmental radiological protection, the experts (those for the protection of man), equipped with the knowledge available, have emphasised man's greater radiosensitivity as compared to the rest of living world. This argument has fed the ICRP recommendations which state that to protect man leads in an implicit manner to a sufficient protection of other living organisms (biota) (ICRP, 1977; 1991), in any case on the population scale (IAEA, 1992; Whicker and Bedford, 1995).

\subsection{Problem: man's protector protects the environment?}

If this argument generally appears realistic in some known situations, it possesses unresolved criticisms and remains, in any case, void of real demonstration. The implementation of a system for environmental radioprotection may only be performed on the basis of an explicit scientific foundation, which is currently lacking.

The ICRP argument is, for example, questioned by the existence of uninhabited zones of the planet or zones which do not lead to immediate exposure to man. The practice of deep water storage of radioactivite waste which is today banned has 
often been cited and has not, to date, led to any direct effects on man but has most probably widely affected the living creatures of the biotope under consideration (Pentreath, 1998).

In protection terms, man and the environment are different in nature entities situated at distinct organisation levels. Environment (its biota in particular) cannot be broken down into one unique species that forms one population of individuals. The result is that radioprotection system of one or the other may not follow the same logic, but they should however remain compatible. On the same scale of ideas, when contaminated by radioactive substances, the environment generally shows a concomitance of non-radioactive chemical pollutants, in such a manner as the protection systems for one or another may not ignore each other and should remain consistent.

As the current worldwide discussion about climate change illustrates, the protection of environment brings the long-term to the forefront with the potential impact on future generations and the risk of impairing the general equilibrium that controls the apparent planetary homeostasis.

The radioprotection of man has constructed a dosimetric system that is essentially based on short-term acute exposure effects from high doses of radiation. Currently, the low dose field is only extrapolated and is the subject of persistent scientific controversy. For man as for the environment, it is particularly important to note that the effects of low dose chronic exposure in a multipollution context increasingly form the core of the problem.

Current dosimetric models generally hypothesize an homogeneous distribution of radioactive nuclides within the organism under study. This leads to the bioaccumulation processes being ignored (at the cell or infra-cell scale, for example), which could become crucial in the understanding of dose/effect relationships. Besides these bioaccumulation phenomena, long-term redistribution phenomena are also taking place within the environmental physical components that could lead to localised accumulation pockets, therefore radioactive vulnerable zones.

The basis of the environmental preoccupation arises from the developing awareness that man is an inherent part of the biosphere and that this later is the home to vital functions for the survival of humankind that need to be respected. Unlike man's protection that is established on a linear logic - from a source to man, passing through the environment - environmental protection requires a "system" approach that incorporates feedback cycling (the global system is closed), and taking into account the complex interactions between the biotope and the living populations (Bréchignac, 2001). The keyword of environmental protection is 
therefore the "ecosystem", that is to say the biosphere's functional unit as a base for vital functions that condition man's survival in this biosphere. In the global ecosystem - the biosphere - it is understood that man has become a participant whose impact is (has become very) significant, but his survival remains linked to respecting the fundamental laws that govern the homeostatic functioning of that ecosystem. This leads to questions on the possible reversal of the ICRP statement, "the environment's protector may protect man", especially in the long-term. In fact, both will be protected given the acknowledgement that humankind is an inherent part of the biota forming the biosphere.

\section{Irradiation by external - internal exposure}

It is important, in a chronic exposure context, to look at the dominant radiation forms, that differ according to the exposure pathways. The most studied is external radiation, that deals with life developing in a contaminated environment, and the risk in that case is much greater for radioactive nuclides that emit $\gamma$. type radiation. The effects of irradiation by internally incorporated radioactive nuclides are much less well-known. They bring bioaccumulation processes into play which are currently the subject of in-depth study (Garnier-Laplace and Paquet, 2000), and the associated risk is greater as it is caused by $\alpha$ or $\beta$. type emitting radioactive nuclides. It is exactly these types of radiation which are more widespread in living creatures' exposure to natural radioactive nuclides in the environment (see Sect. 3).

The bioaccumulation intensity stems from three concomitant processes, the balance of which regulate the pollutant concentration inside the living organism. These are:

- absorption, from the external medium to the internal medium, which brings transport processes through biological barriers (membranes) into play,

- internal distribution, resulting from various transport, fixation or sequestration (irreversible or not) processes,

- excretion.

For non-human living organisms, the bioaccumulation processes have only been studied for some heavy metals on a limited number of animal and plant organisms. A great disparity of mechanisms that lead to bioaccumulation of chemical pollutants exists. The associated toxic effects are also varied according to the observation scale under consideration. The bioaccumulation of radioactive nuclides in non-human living creatures has only been the subject of a very limited number of publications (Pentreath and Lovett, 1976; Guary and Negrel, 1981; Galey et al., 1983; Miramand et al., 1989; Goudard et al., 1991; ChassardBouchaud et al., 1992; Paquet, 1993; Durand et al., 1994; Ribera et al., 1996), and 
more particularly for plants (Gouthu et al., 1999) for which extrapolations have been projected from the behaviour of the corresponding stable elements.

Important questions still remain, as is the case for man, with regards to the relevance of the methodology employed in order to evaluate risk. Is it acceptable to resolve the current knowledge deficiencies, in order to assess the effects of low doses, by means of linear extrapolation of knowledge that has been gained in a high external radiation situation? Or indeed, can one confirm that internal and external irradiation situation produce, with equal energy, the same effects in the living creature? These are two questions that require investigation.

\section{Evaluation of biota exposure levels}

The current data on the exposure levels of fauna and flora to natural radiation or radiation emitted by the presence of radioactive nuclides that contaminate the environment are numerous, but incomplete due to the multiplicity of living organisms (variety of sizes, shapes, habitat, behaviour and movement, etc.). Numerous simplifications had to be adopted, therefore, even in the most studied aquatic environment (IAEA, 1988).

Here the specific difficulty is not the development of an appropriate dosimetric model for a given organism, but rather the essential acquisition of input data on the spatial distribution of radioactive nuclides (IAEA, 1979), both externally as well as within the living organisms (bioaccumulation). Currently, the redistribution processes are still mainly modelled by making an equilibrium hypothesis and therefore by using simple distribution coefficients and concentration factors in the global organism. By means of these assumptions, dose factors have been drafted for several radioactive nuclides in order to lead to an estimation of dose rates for a few organisms in different environments. In the aquatic media, it is generally admitted that simplifications stemming from these assumptions lead to an overestimation of dose rates. However it must be highlighted that such simplifications do not take into account time variations in connection with shortterm fluctuation of the discharge, with the different states of the life cycle, with the behavioural differences, with the seasonal variations of environmental processes, etc. Further to this, although such an estimation of absorbed dose rate may reflect the mean level received by the biota (the fauna and the flora), it does not make up a safe basis for the assessment of total doses received through time. This reserve is also applied to other environmental media (Coughtrey, 1983; IAEA, 1992; Myers, 1989).

As a summary (for detailed references, see UNSCEAR, 1996) in the zones of medium level natural radiation, the dose rates absorbed by the terrestrial plants are 
within the range $0.07-0.8 \mu \mathrm{Gy} \mathrm{h}^{-1}\left(0.6-7 \mathrm{mGy}\right.$ year $\left.^{-1}\right)$, essentially stemming from ${ }^{222} \mathrm{Rn}$ absorbed from the soil water. Aquatic plants are generally found to be subject to absorbed dose rates near to the lower end of this range. The terrestrial animals that are most exposed are those colonising underground habitat. In this case, the rough estimations give, from ${ }^{222} \mathrm{Rn}$ and its disintegration products, $0.25 \mu \mathrm{Gy} \mathrm{h}{ }^{-1}$ for the lungs and around $0.09 \mu \mathrm{Gy} \mathrm{h}^{-1}$ for tissues as for external exposure. In high-level natural radiation zones (thorium and uranium deposits), the absorbed dose rates could go beyond these values by a factor of 1000 . In the aquatic environment, it is ${ }^{210}$ Po that mostly contributes to the dose, with absorbed dose rates through the gonads of some marine animals of around some $\mu \mathrm{Gy} \mathrm{h} \mathrm{h}^{-1}$.

\section{Radiation effects on biota through external irradiation}

A large amount of literature exists on this subject, from the 1960's, which has been the dealt with in several reports often sponsored by international organisations (IAEA, 1976; 1979; 1988; 1992; 1995; NCRP, 1991; Rose, 1992; UNSCEAR, 1982; 1996). This synthesis summarises to the main conclusions illustrated by some selected examples (for detailed references, see UNSCEAR, 1996).

First of all, it is advisable to note that if the radioprotection of man is concentrated on the individual for ethical reasons, a large consensus exists for consideration that in the case of the environment, that is to say the biota it is made up of, it is the populations that should be protected, as a general rule. However, it is often argued that there can be no effect on the population scale (or indeed at the upper levels of organisation, community or ecosystem) if there is no effect on individuals making up this population. In this debate between individuals and populations, it is important to acknowledge the existence of natural populations relying on a dynamic equilibrium that they maintain between themselves and with their biotopes (surroundings), and that ionising radiations only compose an additional stress factor that may influence the equilibrium. It is the reason why environmental radioprotection may only be implemented in full connection with the protection against conventional chemical pollutants.

\subsection{Radiation effects on fauna and flora at the individual level by external irradiation}

These effects have been most studied in high radiation situations.

\section{I.I. On plants}

For plants, literature reports that lethal radiation doses following a high exposure are of between 10 and 1000 Gy. For some lower plant families (mosses and 
lichens), the upper end of this range may reach a higher value. Generally, the large plants are more radiosensitive than the small ones, with a radiosensitivity that lowers from conifers to deciduous trees, thicket species, herbaceous plants, lichens and mushrooms. At lower doses, non-lethal effects were observed, for example, a strong growth inhibition at $40-50 \%$ of the lethal dose or the inhibition of seed production at $25-35 \%$ of the lethal dose. At doses lower than $10 \%$ of the lethal dose, effects are less noticeable, plants showing a normal appearance.

The different parts of plants show distinct sensitivity to radiation, which go from dry seeds (the least sensitive) to the apical meristems (the most sensitive). Plants intended for agriculture show reduction in yield following radiation exposure, with additional modifications induced by external factors (temperature, humidity). Young plants and stressed-plants facing difficult growth conditions may have an increased radiosensitivity.

Plant species also show a range of sensitivity to chronic radiation exposure. For the most sensitive species (pine), dose rates greater than $3000 \mu \mathrm{Gy} \mathrm{h}^{-1}$ for 3 to 4 years reduce growth of needles; in those aged more than one year, the needle length is found to be significantly reduced at a dose rate of $7000 \mu \mathrm{Gy} \mathrm{h}^{-1}$ on one growth season only. Where fully-grown pines are concerned, dose rates from 400 to $2000 \mu \mathrm{Gy} \mathrm{h}^{-1}$ applied for 9 years have produced growth reduction of the trunk. For white oak exposed to chronic gamma radiation, late opening buds were noted as well as an increase in the duration of leaf dormancy. At dose rates greater than $4000 \mu \mathrm{Gy} \mathrm{h}^{-1}$, trees were seen to be more sensitive to greenfly infestation.

From all the data available on the consequences of chronic radiation - which shows the obvious effects on the most sensitive species at around 1000 $3000 \mu \mathrm{Gy} \mathrm{h} \mathrm{h}^{-1}$ with specific modifications at $400-2000 \mu \mathrm{Gy} \mathrm{h} \mathrm{h}^{-1}-$ it is suggested that dose rates in chronic exposure less than $400 \mu \mathrm{Gy} \mathrm{h}^{-1}$ (that is to say around $10 \mathrm{mGy} \mathrm{day}^{-1}$ ) only produce minor effects on some sensitive plants, but remain void of damage for the large majority of plants present in natural communities.

\subsubsection{On terrestrial animals}

Literature concerning radiosensitivity of terrestrial animals is widely dominated by data concerning mammals, which are also the most radiosensitive. Lethal doses for high exposure $\left(\mathrm{DL}_{50 / 30}\right)$ are located at $6-10 \mathrm{~Gy}$ for small mammals, and at 1.5-2.5 Gy for the largest wild and domestic animals. When a total dose of around $\mathrm{DL}_{50 / 30}$ is distributed all along the life-span of an organism (for example $7 \mathrm{~Gy}$ for the mouse, i.e. $420 \mu \mathrm{Gy} \mathrm{h}^{-1}$ or $10 \mathrm{mGy} \mathrm{d}^{-1}$ ), the mean reduction of the life-span was calculated at $5 \%$, and would result from cancer induction (UNSCEAR, 1982). 
There is obviously a variation between species, but there is no indication that when the most exposed individuals are subjected to less than $400 \mu \mathrm{Gy} \mathrm{h} \mathrm{h}^{-1}$, the mortality rate of the corresponding population may be found to be seriously affected.

The reproductive capacity is more sensitive to the effects of radiation than life expectancy (mortality rate). The mammals' reproduction rate may be reduced at doses that only represent $10 \%$ of doses that lead to mortality. A loss of oocytes may occur at $1 \%$ of the lethal dose, but as the production of oocytes is excessive, fertility is found to be little altered. A 25-week exposure from the time of conception at a dose rate of $800 \mu \mathrm{Gy} \mathrm{h}^{-1}$ may lead to the mouse becoming sterile. For the most sensitive mammal studied, the "beagle" dog, a dose of $180 \mu \mathrm{Gy} \mathrm{h}^{-1}$ produced a cellular regression and sterility in a few months, but no damage with exposure reduced to $36 \mu \mathrm{Gy} \mathrm{h}^{-1}$ throughout the life span.

For birds, similar effects to those observed for small mammals were reported. Reptiles and invertebrates are less radiosensitive, but it is advisable to note that such comparisons become arduous due to the notable differences in physiology. The chronic exposure, undergone in a confined space, of a species of lizard with a short-term generation time did not produce any notable effect at a dose rate of $830 \mu \mathrm{Gy} \mathrm{h}{ }^{-1}$ for 5 years. For two other longer generation time species, some individuals of the first species became sterile at $630 \mu \mathrm{Gy} \mathrm{h}^{-1}$ during 3.5 years, and at $210 \mu \mathrm{Gy} \mathrm{h}{ }^{-1}$ during 5.5 years for the other. Adult invertebrates appear to be hardly sensitive in terms of mortality to the effects of radiation exposure. However, the gametogenesis, egg development and juvenile stages are more sensitive.

\subsubsection{On aquatic animals}

Among aquatic organisms, fish are the most sensitive to the effects of radiation and in particular embryos in development stage. The $\mathrm{DL}_{50}$ for high radiation on sea fish is located around 10-25 Gy for investigation periods that reach 60 days after exposure. For the $\mathrm{DL}_{50}$ of sea invertebrates, the upper end of the observed range reaches several hundred grays. Embryos however, are found to be affected at much lower doses, the $\mathrm{DL}_{50 / 30}$ of salmon embryos for example is located at $0.16 \mathrm{~Gy}$.

Where chronic exposures are concerned, dose rates from 10000 to $30000 \mu \mathrm{Gy} \mathrm{h}^{-1}$ have had no effect on the mortality rate of aquatic snails, St. Jacques scallops, clams and blue crabs. Slightly higher dose rates have triggered some effects on the Daphnia pulex population through limiting food. Short-term exposure ( 40 days) of fly fish at dose rates of around $14000-54000 \mu \mathrm{Gy} \mathrm{h}^{-1}$ have shown no radio-induced mortality, but for another neighbouring species, it appears 
that long-term exposure ( $>470$ days) to dose rates greater than $1700 \mu \mathrm{Gy} \mathrm{h} \mathrm{h}^{-1}$ reduced the life-span, in particular for males.

The effects on reproduction make up a much more sensitive indicator for the response to radiation of aquatic organisms. The reproductive capacity of the fresh water snail Physa heterostropha and the sea polychaet worms Ophriotrocha diadema and Neanthes arenaceodentata was found to be reduced during chronic exposure to dose rates of around $3200-7000 \mu \mathrm{Gy} \mathrm{h}^{-1}$. A dose rate of $7300 \mu \mathrm{Gy} \mathrm{h}^{-1}$ sterilises, in 50 days, the male fresh water fish Ameca splendens, and a dose rate of $1700 \mu \mathrm{Gy} \mathrm{h}^{-1}$ applied throughout the life of some "guppy fish" couples (Poecilia reticulata) significantly reduced the duration of egg production. It was deduced that significant effect on fish gonads following chronic radiation only really began to appear from $1000 \mu \mathrm{Gy} \mathrm{h} \mathbf{h}^{-1}$.

\subsubsection{Classification of radiosensitivity}

As the source of radiation effects on living organisms is at the level of interactions and non-repaired damages at the cellular and the molecular scale, it was logical to search for a classification established upon chromosome criteria (Sparrow et al., 1967; Whicker and Schultz, 1982) which however, were not found to be very discriminating, a feature which suggests that other non-identified parameters should also be included. These studies however, enabled production of an approximate hierarchy of the radiosensitivity of the life kingdom to strong (lethal) doses which places mammals, including man, among the most radiosensitive, and primitive organisms (bacteria, protozoa, viruses) among the most resistant (Fig. 1).

\subsection{Effects of radiation on plants and animals at the level of population by external irradiation}

\subsubsection{What do we know nowadays?}

The effects of radiation on the life kingdom at the upper organisation levels population, communities and ecosystems - are much less documented as they have only been the subjects of rare and spot studies. These studies mainly come from in situ irradiation experiments, from experimental enclosures in nature intended to follow the dynamics of some animal populations, or indeed observations carried out in zones subjected to increased levels of radiation originated naturally or anthropically (zones contaminated by waste storage or accidental radioactive discharge). The main difficulty inherent to all these studies is found in the notorious absence of real controls that considerably hinders an unambiguous interpretation of the observation. 


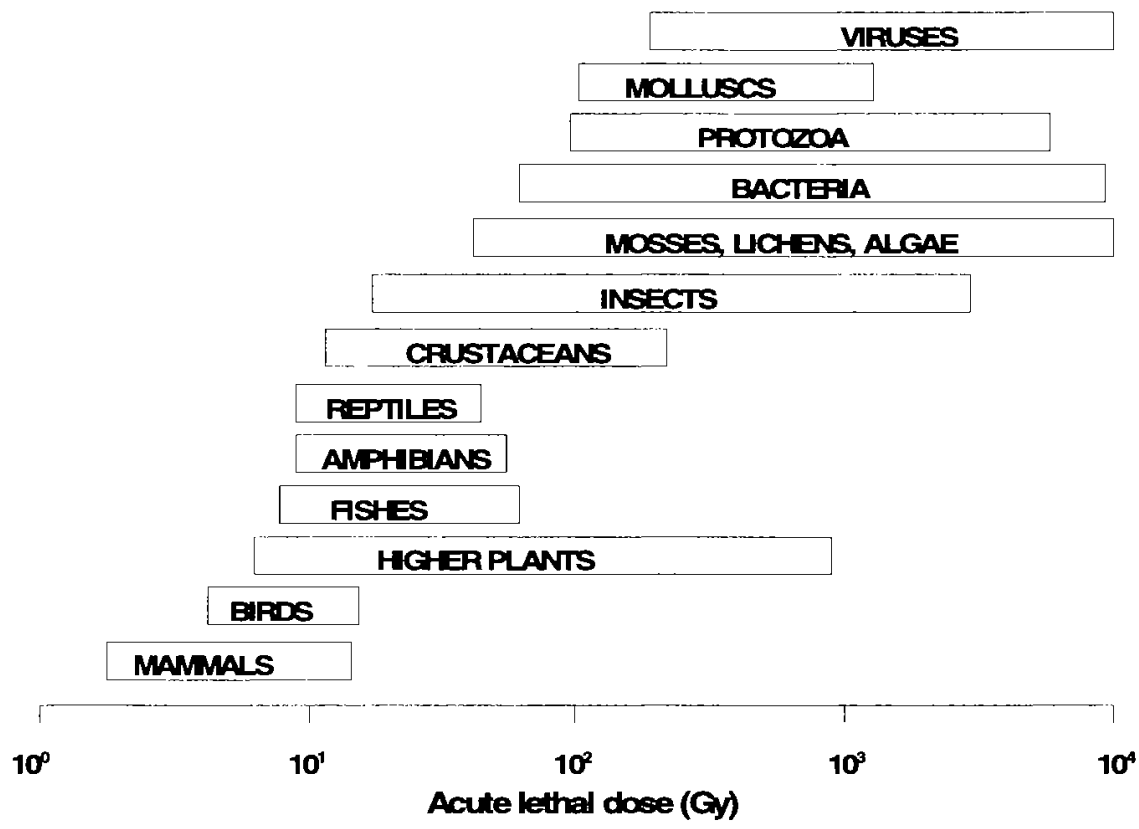

Figure 1 - Radiosensitivity in acute exposure of the main classes of living organisms (taken from Whicker and Schult, 1982).

Radiosensibilité en exposition aiguë des principales classes d'êtres vivants (d'après Whicker et Schultz, 1982).

The Pinus type conifers are shown to be the most sensitive of the plant species studied, whether it is a case of strong or chronic exposure, and the communities of this type of plant are also the most radio-sensitive amongst those for which data is available. In general, a forest where the pine is dominant (or co-dominant) suffers little at doses of $1-5 \mathrm{~Gy}$ in acute exposure or at dose rates of $400-4000 \mu \mathrm{Gy} \mathrm{h}^{-1}$ through chronic exposure. In this context, the minor effects observed are small modifications of productivity and reproduction, which disappear when the radiation source is taken away. Severe effects on the conifer forest may intervene at doses of more than $20 \mathrm{~Gy}$ in acute exposure, or at dose rates of more than $40000 \mu \mathrm{Gy} \mathrm{h}^{-1}$ in chronic exposure. Such effects lead to mortality of almost all the upper level plants and the ecosystem could only recover, if this is at all possible, after several decades. Other types of communities of plants can stand dose rates at least of one order of magnitude greater before showing similar effects (Tab. I). It must be highlighted here that knowledge of total absorbed dose is insufficient in order to correctly characterise the effects of radiation on living communities as it is also necessary to clarify its variation in time 
TABLE I

Ranges of high irradiation doses leading to three degrees of damage (minor, intermediate and severe) in communities of plants.

Gammes des doses en irradiation aiguë produisant trois degrés de dommages (mineurs, intermédiaires et sévères) aux communautés végétales.

\begin{tabular}{lccc|}
\hline \multirow{2}{*}{ Community of plants } & \multicolumn{2}{c|}{ Dose range to produce effects $(\mathbf{G y})^{\mathbf{a}}$} & \\
\cline { 2 - 4 } & Minor effects & Intermediate effects & Severe effects \\
\hline Coniferous forest & $1-10$ & $10-20$ & $>20$ \\
Deciduous forest & $10-100$ & $50-350$ & $>100$ \\
Shrubland & $10-50$ & $50-200$ & $>200$ \\
Tropical rain forest & $40-100$ & $100-400$ & $>400$ \\
Rock outcrop & $80-100$ & $100-400$ & $>400$ \\
Old field (fallow fields) & $30-100$ & $100-1000$ & $>1000$ \\
Herbaceous forest understorey & $200-400$ & $400-600$ & $>600$ \\
Grassland & $80-100$ & $100-1000$ & $>1000$ \\
Herbaceous invaders & $400-600$ & $600-1000$ & $>1600$ \\
Moss and lichen & $100-1000$ & $500-5000$ & $>2000$ \\
\hline
\end{tabular}

${ }^{a}$ Exposure duration from 8 to 30 days. The daily equivalent dose ranges for the effects of chronic exposure are located between 1 and $4 \%$ of the values given in the table (taken from Whicker and Schultz, 1982).

(that is to say the dose rate and the duration of exposure). An exposure thus, for example, of one day of a total of $7 \mathrm{~Gy}$ has triggered the same effects (mortality for pine trees) as an exposure of 70 Gy spread out over a period of one year.

Due to their mobility, the effects of radiation on animal populations are difficult to appreciate, and this even more so as they depend on the communities of plants with which they are associated in the ecosystem. Taking into account the compensation and adjustment phenomena for stress which intervene in the animal communities, the current position is to think exposures only resulting in minor effects to the most exposed individuals only have a slight chance of triggering repercussions through the scale of the population. In order to appreciate the effects of radiation, the reproduction indicators are more sensitive than those that rely on mortality rate. Amongst the different species, mammals are the most radiosensitive. On this basis, it is considered that dose rates less than $100 \mu \mathrm{Gy} \mathrm{h}^{-1}$ to which the most exposed individuals would be subjected in chronic exposure only have a slight chance of setting off noticeable effects on the majority of terrestrial animal communities. It has also been concluded that to subject a small fraction of the individuals of an aquatic population to doses of less than $400 \mu \mathrm{Gy} \mathrm{h}^{-1}$ would not have any noticeable repercussion on the scale of this 


\section{TABLE II}

Classification of distinct zones of manifestations of ionising radiation effect in chronic exposure according to increasing dose rates (taken from Polikarpov, 1998).

Classification de zones distinctes de manifestations d'effets d'exposition chronique aux rayonnements ionisants selon des débits de dose croissants (tiré de Polikarpov, 1998).

\begin{tabular}{|lc|}
\hline \multicolumn{1}{|c|}{ Zone of effect manifestation } & Dose rate - Gy year $\left(\mathrm{mGy} \mathrm{d}^{-1}\right)$ \\
\hline Obvious effects & $4->3000(11-8.200)$ \\
Ecological masking zone & $0.05-4(0.1-11)$ \\
Physiological masking zone & $0.005-0.05(0.01-0.1)$ \\
"Well being" zone (natural radiation levels) & $0.00004-0.005(0.0001-0.01)$ \\
Uncertainty zone & $<0.00001-0.00004(<0.00003-0.0001)$ \\
\hline
\end{tabular}

population. It must however be highlighted that recent studies carried out in contaminated zones in Russia have reported detectable effects observed at lower doses $\left(100 \mu \mathrm{Gy} \mathrm{h}^{-1}\right.$, Kryshev and Sazykina, 1998; these authors attribute them to the synergetic presence of other pollutants; $240 \mu \mathrm{Gy} \mathrm{h}^{-1}$, Tsytsugina, 1998).

Despite the existence of considerable uncertainty concerning the assessment of consequences of accidental situations, the analysis of their effects on the biota of the environment is generally quite in agreement to the other approaches, whether it addressed the study of natural zones subject gamma sources which were placed there, or rare experimental work carried out under controlled conditions. If no extinction of species has been mentioned that may be attributed to ionising radiation, with the overview available to us, persistent noticeable effects are observed, as for example, the reduction, that is still observed, of soil invertebrate population size in the south-east Ural 30 years after the Kyshtym accident (1957). Homeostatic adjustments have often been recorded with the frequent manifestation of repair processes, in such a manner that the populations, at least for the current observations that may be accessed to nowadays, continue to survive even in a long term chronic exposure situation (Kryshev, 1992; Taskaev et al., 1992; Arkhipov et al., 1994).

Interesting conceptual classification work concerning the effects of ionising radiation on the entire spectrum of dose rates that may currently be met on the planet's surface has recently been performed by Polikarpov (1998). This author identifies, in particular, 5 zones with increasing dose rate (Tab. II) which he connects to effects located at the different organisational levels, from cells right up to ecosystems. This argument, however, relies on the important basic assumption that there is a more or less linear relationship between radiosensitivity and the organisational level, a feature that remains to be demonstrated. 


\subsubsection{The difficulties of a holistic approach to the ecosystem}

There are inherent difficulties in acquiring information on the large number of species and living communities which make up the biosphere, on the various environmental factors - either of a natural or anthropogenic origin - which interfere with them, and on the characteristic time of effects which only manifest themselves in the long term through successive generations (hereditary effects). This statement is general and deals as much with the field of radiotoxic effects as that of conventional chemical toxic effects. In addition to this, the acquisition of adequate dosimetric information is hindered by complex source distributions and by the movement of living organisms in the environment.

The exposure of natural living communities to radiation, which include organisms showing a large range of radiosensitivities, may only set off direct and immediate damage to the most sensitive species. It must however be highlighted that the other species may be indirectly affected, for example through the loss of their habitat or by means of the competitive advantage gained. For any stress situation in an ecosystem, like exposure to radiation for example, it is quite possible if not probable that a complex sequence of rupture of equilibrium, of adjustment and then reaching a new state of equilibrium takes place. The different response stages of an ecosystem to any stress whatsoever do indeed begin with the initial altering of the most sensitive components, followed by the development of repair mechanisms intended to remove the effects of stress, finally leading to either a re-balancing of the functioning (homeostasis restoration) or to a fatal divergence.

Radiosensitivity of individuals is only one of the factors that enable the effects of radiation on populations and ecosystems to be appreciated. Laboratory observation, most often concerning individuals, may therefore suffer from a lack of environmental representativity where additional stress like competition and predatian (indeed the presence of other pollutants) is common. If compensation mechanisms able to reduce radio-induced damage on the rate of survival or reproduction can exist (Sazykina, 1996), there are also several indirect effects that may reduce the apparent benefit to nothing. Modifications in plant cover, for example, may affect animal communities. When plants die in a highly irradiated zone, herbivore animal and insects' food and, therefore, their predators', is found to be reduced. These animals may disappear and be replaced by other species that live in a dead environment. The greenflies have been thus attracted to an irradiated forest of pines and oaks, and bark beetle overrun the trees in a tropical forest when the natural defence processes are lowered. This may eventually lead to insects damaging or even killing the trees that would otherwise survive.

It is therefore very likely that the assessment of the effects of radiation at the scale of communities and ecosystems may not be derived only from the effects 
observed at the scale of individuals. Typically, measurable parameters that deal with the scale of populations are the number of individuals, their mortality, reproduction and growth rates. On the scale of ecosystem, it is the changes in functioning which are usually taken into account, such as the loosening of nutrient recycling, the modification of primary production, the reduction in biodiversity, the replacement of natural succession by regression, the reduction in average size of living organisms, or other indicators such as the incidence of illness. These two measurable parameter categories are obviously strongly linked, but today there is no consensus on the scientific relevance of useful parameters suitable to cover environmental radioprotection from individuals up to ecosystems.

The scientific bases for a comprehensive understanding of the effects of radiation on biota at higher scales of organisation have therefore not yet been obtained. Several questions remain, which partly explains the lack of an international regulatory framework that sets the standards in matters of environmental radioprotection. Located at the top of the scale of complexity of living creatures, ecosystems are complex integrators. In real situations, other pollutants whose combined effects on the internal processes are practically unknown almost always accompany radiopollution to which they may be subject. Recent studies have indeed showed the existence of synergic responses (Sugg et al., 1995; Ausseil et al., 2000; Fraysse et al., 2000), the ecological and evolutionary significance of which may be considerable. Finally, it may be increasing highlight importance to the effects which could appear in the long term, that is to say those which by largely exceeding the individual scale, may, through their reproduction, be expressed much later on the population scale. If the reproduction criteria are shown to be amongst the most radiosensitive parameters, it must also be acknowledged that the genetic damage appears at even lower exposure levels, and the implication in the long term of such an observation is unknown. The example of a recent study on populations of rodents near Chernobyl (Baker et al., 1996) may be given, which shows a clear change in the DNA coding for the mitochondrial cytochrome $b$, without the population appearing to be affected up until today. One may be right to ask if doses that are too low to affect reproduction could, however, in the long term, make up a mutational pool sufficient in the population to alter its normal course of evolution (Whicker and Hinton, 1996).

\subsubsection{What are the current gaps in scientific knowledge?}

The American Department of Energy (DOE), on the basis of current knowledge, suggested, in 1996, a regulation for the "radiological protection of the public and environment" in order to integrate this in the Federal Regulation Code (10 CFR 834). This suggestion included, in particular, a rule of limitation of dose rates to 
$10 \mathrm{mGy} \mathrm{d}^{-1}$ for terrestrial plants, recently extended to aquatic animals, and to $1 \mathrm{mGy} \mathrm{d}^{-1}$ for the terrestrial animals. Their authors, however, highlighted that the implementation of such regulation poses major problems (Whicker and Hinton, 1996):

(1) these dose limits rely on a hypothesis that has not yet been demonstrated that reproduction, measured by the usual standard methods, makes up the most critical limiting criterion,

(2) the question of the necessary practical framework intended to assess and control these limits is still very problematic.

By concluding, "if these limits appear reasonable on the basis of current knowledge, our understanding of the ecological and evolutionary significance of sub-cellular and molecular modifications induced by ionising radiation is much too low to be ignored", they recommended that effort be concentrated primarily on research to fill in knowledge deficiency.

The first current deficiency deals with the poor knowledge on dose/effect relationships at the scale of populations and ecosystems (an aspect that is otherwise still little formalised on the scale of individuals). Recent publications on the subject have been pressing forward the requirement to acquire this type of knowledge (Pentreath, 1998; Kryshev and Sazykina, 1998; Sazykina, 1996; Tsytsugina, 1998; Whicker and Hinton, 1996). Only a few studies were carried out on-site on natural contaminated sites, but the breadth of their conclusions (as mentioned above) is rendered considerably fragile by the absence of controls, a characteristic which is inherent to this descriptive approach. The second deficiency, also frequently highlighted in literature, deals with long term effect (one generation - the lifetime of an organism - or more) of chronic exposure of biota to low doses in a multipollution context. As has already been mentioned, recent work shows that the combination of radioactive pollutants with conventional chemical pollutants does indeed display synergies or antagonisms at the transfer level, and therefore most probably at the effect level too.

Finally, it is important to strengthen that up until now a clearly organised framework did not exist at the international level upon which a consensual system of environmental protection can be developed against ionising radiation. It seems, however, that this process is being implemented at the turn of this millennium (see hereafter). A prerequisite be correctly defining the question is to clarify its different aspects: why protect the environment, which elements of the environment should be protected (biotic and/or abiotic), which dosimetry faced with the multiplicity of living organisms, which quantifiable criteria, which units, etc. 


\section{Which environmental dosimetry?}

The anthropogenic discharge of radioactive waste in the atmosphere, in the aquatic systems or their storage in terrestrial dumps, leads to an increase in radiation exposure levels of the fauna and flora. The chronic exposure levels (continuous exposure) are located at absorbed dose rates which do not generally go beyond $100 \mu \mathrm{Gy} \mathrm{h}^{-1}$ and only exceptionally reach several thousand $\mu \mathrm{Gy} \mathrm{h} \mathrm{h}^{-1}$. These exposures to additional radiation are higher than the average natural level of radiation, but are always generally located within the levels that may be met in zones having high levels of natural radiation. If one considers the fact that storage of waste makes up point sources and that discharges are usually found to be dispersed or diluted, such dose rates only really concern one small section of individuals of any population whatsoever. The mean dose rate for the population would really be much less (Woodhead, 1984).

Altogether, the conclusions given above (as well as in Sect. 4) only concern, however, the effects of radiation with low lineic energy transfer $(\beta$ and $\gamma$ radiation). When exposure includes a significant part coming from high lineic energy transfer radiation ( $\alpha$ particles), it becomes necessary to counterbalance this component of the absorbed dose (RBE: Relative Biological Effectiveness), and therefore to use a total balanced absorbed dose in order to appreciate their effects. The actual knowledge of $\alpha$ radiation effects on biota is insufficient to be able to correctly locate one acceptable value for this counterbalancing factor; its value has been set at 20 for man (for the calculation of the equivalent dose), but certain authors have suggested a value of 5 would be more advisable for aquatic organisms. The definition of this RBE factor also goes against existence of very different radio-sensitivities within one same living organism. We know, for example, that in the case of trees, the meristems (located at the apex of the shoots) are much more radiosensitive than the wood.

Furthermore, as it is the case for man, the $\alpha$ emitting natural radioactive nuclides seem to constitute a preponderant source of exposure to natural radiation for the majority of living wild organisms. This strengthens the requirement to obtain better knowledge of the distribution of these radioactive nuclides in the potential targets (bioaccumulation) and to finely tune realistic models for the estimation of absorbed doses.

These difficulties show that the relevance of an environmental dosimetry for which concepts would be similar to those which have been finely tuned in order to evaluate risks to man is not yet clearly established. 


\section{Approaches to radioprotection criteria}

After years of the "wait and see" policy where the reviews of available scientific matter succeeded one another, a real desire appeared at the turn of this millennium on the international scale to go on towards a consensual definition of a system of environmental radioprotection, that is to say which goes beyond only the protection of man by taking into account all living beings and their surroundings (OSPAR, 1998). In this aim, two major difficulties must be overcome: on the one hand, to design a system which remains compatible with the radioprotection system for man, and on the other hand, which is also in agreement with the approaches implemented for protection against non-radioactive conventional chemical toxicants (ecotoxicology and environmental toxicology).

Current international work, in addition to national policies which have already been developed, most very recently, in some countries (USA, Russia, Canada, Sweden), are not yet structured in a clear coordination context.

\subsection{The "Environmental protection" taskgroup of the ICRP}

During the "Main Commission" Meeting in Saint-Petersburg, in 1999, the suggestion to form a taskgroup on Environmental Radioprotection was drafted. The general aim assigned to the taskgroup was to develop a protection policy and to set down a general framework for environmental protection that is based on ethical and philosophical principles. In particular, in the long run, it should introduce this conceptual framework into the next ICRP recommendations. The practical aim intends to produce a document that would prepare the introduction of major ideas into the new ICRP recommendations in 2003. Started at a first meeting held in Stockholm in November 2000, the taskgroup is currently elaborating the structure and content of a future document to be drafted.

Issues dealt with in particular were the definition of the aim of ecosystem and living species protection, that is to say the environment. It is acknowledged that the biotic and abiotic systems are both implicated, and that it is important to retain biodiversity. It is also mentioned that from an ethical point of view, one may consider that it is human responsibility not to alter ecosystems and related species in an unreasonable manner. Such an approach enables an exit from the vicious circle of trying to determine whether one should protect the environment for itself or for the interest of man. If we protect living species for ethical reasons we also induce a sustainable environment for future generations of all species. Another question consists of identifying if protection should target individuals or populations. It may be that either case is justified in separate situations. The "wild" populations should no doubt be distinguished from domestic populations, in 
particular for food. It could eventually become necessary to define reference organisms or populations, or even biospheres, in order to access necessary practical evaluation criteria.

\subsection{The International Union of Radioecology Workgroup}

The IUR (more than 600 subscriptions throughout forty or so countries) initiated a first Workgroup in 1998 through a Concerted Action of the European Commission for which work was published in a technical note entitled "Doses and effects in non-human systems" (IUR, 2000). The IUR currently continues this effort by the implementation of a newer, broader, Workgroup entitled "Environmental protection: Exposure and effects in Biota" which should investigate ethical aspects, questions of exposure dosimetry and dose/effect relationships leading to the implementation of standards. This thought process work, drafted on the pioneering approach developed by Pentreath $(1998 ; 1999)$ and Pentreath and Woodhead (2000), has in particular enabled, independantly the emergence of two European projects that have recently been accepted by the European Commission, FASSET and EPIC in the 5th Framework Programme. The Union, amongst other things, is currently researching a position of international coordination and to this end, feeds several discussions with the IAEA.

\subsection{The actions of the IAEA}

After having undertaken several reviews of the available scientifique literature, the IAEA efforts have recently been orientated toward promotion of expert discussions on the subject of ecological risk assessment in the aim of elaborating concepts that may lead to identification of standards, criteria and recommendations for environmental protection against ionising radiation (IAEA, 1999). The latest expert meeting, held in Vienna in August 2000 (22 countries represented) undertook a thought process around three parallel plans: the ethical principles and dimensions, the target end-point specification and finally questions related to the definition of units, quantities and verification. A review of different national approaches shows that only 3 countries, USA, Canada and Sweden, have currently tried to develop a system of environmental radioprotection that is more elaborate than the current ICRP recommendation (IAEA, 2000).

\subsection{The European projects of the EC 5th Framework Programme}

\subsubsection{FASSET “Framework for Assessment of Environmental Impact”}

The aim of this project consists of defining and providing the radiological protection with a philosophy and a general framework for assessment of impact on 
the environment. By relying on a set of reference models including target organisms and ecosystems, this general framework will gather together in a homogeneous and compatible manner the current knowledge about sources, exposure, dosimetry and effects on the environment. The relevant components of this general framework will be identified on the basis of an "ecosystem" approach, in order to identify organisms and appropriate end-points, thanks to systematic consideration of all data available and if necessary upon the expert's judgement. The project currently relies on the skills of 15 European partners.

\subsubsection{EPIC "Environmental Protection from Ionising Contaminants in the Arctic"}

The main objective of this project consists of developing a methodology for the radiological protection of populations of living organisms in the arctic ecosystems by identifying criteria and limit doses. The project relies on the skills of 4 partners, 2 of which are Russian.

\subsection{Some relevant national approaches}

\subsubsection{United-states of America (DOE)}

The American DOE has already implemented a dose limit for the protection of aquatic organisms and currently plans to define standard doses for terrestrial organisms. In order to respond to method and advice requirements for the application of these standards, the DOE has erected a "graded approach" in order to assess doses for biota which can be broken down into 3 successive phases:

(1) definition of the assessment zone and collection of information on concentrations of radioactive nuclides,

(2) application of a simple methodology based on general "screening" which identifies concentrations limits in radioactive nuclides in soils, in sediments and in water ("BCGs": Biota Concentration Guides),

(3) if necessary, a special analysis of the site fed by data which are specifically issued from it. This system relies entirely on values attributed to dose rate limits such as those given above (10 and $1 \mathrm{mGy} \mathrm{d}^{-1}$; DOE, 2000).

\subsubsection{Canada - Canadian Nuclear Safety Commission (CNSC)}

The federal and provincial Canadian laws on environmental protection (Environmental Protection Acts) have set down a general framework for which the main themes are as follows: prevention of all pollution, the objective of not triggering significant damage to the environment, the implementation of an 


\section{TABLE III}

Rough summary of "no effect estimated values" used for the assessment of radiation impact to biota around Canadian nuclear facilities (P. Thompson, personal communication).

Récapitulatif sommaire des « valeurs estimées sans effet » utilisées pour l'évaluation de l'impact des radiations au biota autour des installations nucléaires canadiennes (P. Thompson, communication privée).

\begin{tabular}{lcl}
\hline \multicolumn{1}{c}{ Taxonomic groups } & Realistic "No effect estimated values" (Gy year ${ }^{-1}$ ) \\
\hline Fish & 0.2 \\
Benthic invertebrates & 0.6 \\
Algae and macrophytes & 0.88 \\
Amphibians & 0.08 \\
Small mammals & 0.4 \\
Plants and terrestrial invertebrates & 0.88 \\
\hline
\end{tabular}

ecosystem approach, the minimising to "acceptable levels" of impact taking into account the socio-economical factors (ALARA), the multiple implication of stakeholders in the risk analysis process. In Canada, the main concern is linked with uranium mines, and the impact assessment methodology relies upon the "no effect estimated values", as much for chemical toxicity as for the effects of radiation. In the case of assessment of radiation toxicity around Canadian nuclear facilities, these "no effect estimated values" are located between 0.1 and $1 \mathrm{~Gy}$ year $^{-1}$ (rough summary, Tab. III). The Relative Biological Effectiveness factor (RBE, acknowledging the highest toxicity of high lineic energy transfer radiation) was set in a conservative manner to a value of 40 for the $\alpha$ particles and to 3 for $\beta$ radiation from tritium.

\subsubsection{Sweden}

Since 1999, the Swedish Environmental Code which sets the legal framework in matters of environmental protection has clearly stated the philosophy, the aims and the methods intended to protect the environment from poisonous effects from all polluting sources or activities, radioactive or not. The aim of this Environmental Code is to promote a "sustainable development" through: protection of health, protection of valuable environments, protection of biodiversity, protection of terrestrial and aquatic environments taking into account the sustainability principle founded on ecological, social, cultural and economical aspects. An impact assessment methodology is currently being developed to lead to standards and criteria. It is within this context that the Swedish Radiation Protection Institute (SSI) has initiated the FASSET project for which it is coordinator. 


\section{Conclusions}

The few currently existing concrete approaches for environmental radiological protection are based on dose limits (10 and $1 \mathrm{mGy} \mathrm{d}^{-1}$ ) which have been determined from literature dealing with the effects of acute exposure to external radiation on individuals. In this case the standards have been taken from a context far from the current environmental reality where, most often, contamination is diffused and residual, that is to say, it subjects the living creatures to low doses in a chronic manner, over several generations. In addition to this, the current environmental reality is also characterised by multipollution for which the consequences in terms of effects are still largely unknown.

Social pressure currently being put upon the necessity to take into account radiological environmental protection in an explicit manner is today coming up against large deficiency of knowledge that a scientist should take to task. It is not however desirable to wait for this knowledge to become available in order to implement a consensus system of environmental radioprotection. It is useful, when faced with this apparent paradox, to issue some directing principles that should orient development of such a system. First of all it is essential that this system remains compatible with that of the protection of man, in order to avoid recommendations from one contradicting recommendations from the other. In the same manner, environmental protection against ionising radiation should be able to be inserted within the general context of environmental toxicology and even more so as certain radioactive nuclides show, besides their radiological harm, a high chemical toxicity (uranium, for example).

Finally, the reliability of the future environmental radioprotection system will only be ensured if its scientific basis is solid, which reinforces the need to undertake relevant research in order to fill current deficiencies. Some themes to be developed in synergy may be drafted. First, to complete radioecological knowledge of transfers by a better knowledge of the distribution of the radioactive nuclides in living organisms, that is to say, their "bioaccumulation" at tissue, cellular and molecular levels. This constitutes the key to the correct appreciation of exposures. Second, to study the effects of this bioaccumulation in a context of multipollution at low chronic doses (long exposure times), (Garnier-Laplace and Paquet, 2000). Third, to identify the characteristics of the effects (of these low doses, in chronic multipollutions) on the scale of the "ecosystem", in such a manner not to neglect their consequences on emerging functional processes which characterise this organisational scale (Anon, 1996; Taub, 1997; Fuma et al., 1998; 2000; 2001; Hinton and Pinder, 2001; Bréchignac, 2001). This last approach relies on the simplified laboratory model ecosystems. These, more accessible for control, enable the solution of a good number of stumbling blocks that the "ecosystem" 


\section{F. BRÉCHIGNAC}

in situ approaches come up against: controllable, they enable real control experiments to be performed and limit sources of variability and uncertainty; duplicable and repeatable, they promote indispensable statistic assessment; possessing an apparent homeostasis as on the scale of the biosphere, they make up a representative model of the environment that is more relevant than individuals only and enable exploration of genetic effects which go through successive generations.

Acknowledgements. The author whishes to thank Karine Beaugelin-Seiller, Philippe Calmon, Jean-Christophe Gariel, Jacqueline Garnier-Laplace, Henri Métivier and Pascal Santucci for critically reading the manuscript. Linguistic editing has been kindly granted by Francis Denison.

\section{REFERENCES}

Anon (1996) Standard practice E1366-91: Standardized aquatic microcosms - Fresh water. Vol. 11.05 (Water and Environmental technology: Biological effects and Environmental Fate; Biotechnology, Pesticides), Annual Book of ASTM Standards, pp. 734-768.

Arkhipov N.P., Kuchma N.D., Askbrant S., Pasternak P.S., Musica V.V. (1994) Acute and long-term effects of irradiation on pine (Pinus sylvestris) stands post-Chernobyl, Sci. Tot. Environ. 157, 383-386.

Ausseil O., Garnier-Laplace J., Baudin J.P., Casellas C., Porcher J.M., Lange A. (2000) Effects of cadmium and zinc exposure of rainbow trout on the organism's radionuclide contamination dynamics. In: Proceedings of the Third World SETAC Conference, May 21-25, 2000, Brighton, $U K$.

Baker R.J., van den Bussche R.A., Wright A.J., Wiggins L.E., Hamilton M.J., Reat E.P., Smith M.H., Lomakin M.D., Chesser R.K. (1996) High level of genetic changes in rodents of Chernobyl, Nature 380,707-708.

Bréchignac F. (2001) Environment versus man radioprotection: the need for a new conceptual approach. In: International Congress on radioecology and ecotoxicology of terrestrial and estuarine environments ECORAD 2001, September 3-7, 2001, Aix-en-Provence, France, Radioprotection Colloque, in press.

Chassard-Bouchaud C., Galle C., Lopez-Rabereau E. (1992) Aluminium bioaccumulation in the brown trout Salmo trutta fario from acidified streams: a structural, ultrastructural and microanalytical study, Rev. Sci. Eau 5, 37-54.

ICRP Publication 26 (1977) Recommendations of the International Commission on Radiation Protection, Pergamon Press, Oxford.

ICRP Publication 60 (1991) Recommendations of the International Commission on Radiation Protection, Ann. ICRP 21, Pergamon Press, Oxford.

Coughtrey P.J. (1983) Effect of ionizing radiation on native plant and animal communities, ANS 305.

DOE Standard (2000) A graded approach for evaluating radiation doses to aquatic and terrestrial biota, US Department of Energy, Washington DC 20585, projet number ENVR-0011.

Durand J.P., Milcent M.C., Goudard F., Paquet F., Germain P., Nafissi T., Piéri J. (1994) Chemical behaviour of three radionuclides (cesium, americium and technecium) and their uptake at the cytosolic level in aquatic organisms, Biochem. Molecul. Biol. Inter. 33, 521-534. 
Fraysse B., Baudin J.P., Garnier-Laplace J., Boudou A. (2000) Validity field of bivalves as radioindicators in freswater ecosystems within a mutipollution context $(\mathrm{Cd}, \mathrm{Zn})$. In: Proceedings of the Third World SETAC Conference, May 21-25, 2000, Brighton, UK.

Fuma S., Takeda H., Miyamoto K., Yanagisawa K., Inoue Y., Sato N., Hirano M., Kawabata Z. (1998) Effects of $\gamma$-rays on the populations of the steady-state ecological microcosm, Int. J. Radiat. Biol. 74 (1), 145-150.

Fuma S., Takeda H., Miyamoto K., Yanagisawa K., Inoue Y., Ishii N., Sugai K., Ishii C., Kawabata Z. (2000) Simple aquatic microcosm for ecotoxicity screening at the community level, Bull. Environ. Contam. Toxicol. 65, 699-706.

Fuma S., Takeda H., Miyamoto K., Yanagisawa K., Inoue Y., Ishii N., Sugai K., Ishii C., Kawabata Z. (2001) Ecological evaluation of gadolinium toxicity compared with other heavy metals using aquatic microcosm, Bull. Environ. Contam. Toxicol. 66, 231-238.

Galey J., Goudard F. Piéri J., Fowler S.W., Carvalho P. (1983) Tissue and subcellular distribution of ${ }^{252} \mathrm{Cf}$ and ${ }^{241} \mathrm{Am}$ in the seastar Marthasterias glacialis. Mar. Biol. 75, 253-259.

Garnier-Laplace J., Paquet F. (2000) Bioaccumulation of radioactive nuclides in situations of chronic exposure of ecosystems and persons of the public. ENVIRHOM Project, Report IPSN-DPRE 2000-01/DPHD 2000-03, October 2000.

Goudard F., Durand J.P., Piéri J., Masson M., George S. (1991) Subcellular loclization and identification of ${ }^{95 \mathrm{~m}} \mathrm{Tc}$ and ${ }^{241} \mathrm{Am}$. Binding ligands in the hepatopancreas of the lobster Homarus gammarus, Mar. Biol. 108, 411-417.

Gouthu S., Weginwar R., Arie T., Ambe S., Ozaki T., Enomoto S., Ambe F., Yamaguchi I. (1999) Subcellular distribution and translocation of radionuclides in plants, Environ. Toxicol. Chem. 18, 2023-2027.

Guary J.C., Negrel R. (1981) Calcium phosphate granules: a trap fro transuranics and iron in crab hepatopancreas, Comp. Biochem. Physiol. 68A, 423-427.

Hinton T.G., Pinder J.E. (2001) Comparative Kinetics of Cesium from Whole-lake, Limnocorral and Laboratory-scale Experiments. In: International Congress on radioecology and ecotoxicology of terrestrial and estuarine environments ECORAD 2001, September 3-7, 2001, Aix-enProvence, France, Radioprotection Colloque, in press.

IAEA (1976) Effects of ionising radiation on aquatic organisms and ecosystems, Technical Report Series $N^{\circ} 172$, Vienna, Austria.

IAEA (1979) Methodology for assessing impacts of radioactivity on aquatic ecosystems, Technical Report Series $N^{\circ} 190$, Vienna, Austria.

IAEA (1988) Assessing the impact of deep sea disposal of low level radioactive waste on living marine resources, Technical Report Series $N^{\circ} 288$, Vienna, Austria.

IAEA (1992) Effects of ionizing radiation on plants and animals at levels implied by current radiation protection standards, Technical Report Series N³32, Vienna, Austria.

IAEA (1995) The principles of radioactive waste management, Safety Series $N^{\circ} 111$, Vienna, Austria.

IAEA (1999) Environmental protection from the effects of ionizing radiation. A report for discussion, IAEA TecDoc 1091, Vienna, Austria.

IAEA (2000) Report of the Specialists' Meeting on Environmental protection from the Effects of Ionizing Radiation: International perspectives, Ref. 723-J9-SP-1114.2, 29 August I September, 2000, Vienna, Austria.

IUR (2000) Doses and effects in non-human systems. Summary of the Work of the Action Group of the International Union of Radioecology. (IUR) NRPA, P.O. Box 55, N-1332, Østerås.

Kryshev I.I. (1992) Radioecological consequences of the Chernobyl accident, Nuclear Society International, Moscow. 


\section{F. BRÉCHIGNAC}

Kryshev I.I., Sazykina T.G. (1998) Radioecological effects on aquatic organisms in the areas with high levels of radioactive contamination: environmental protection criteria, Rad. Protect. Dosim. 75 (1-4), 187-191.

Miramand P., Germain P., Trilles J.P. (1989) Histoautoradiographic localisation of ${ }^{241}$ Am in tissues of european lobster Homarus gammarus and edible crab Cancer pagurus after uptake from labelled seawater, Mar. Ecol. Prog. Ser. 52, 217-225.

Myers D.K. (1989) The general principles and consequences of environmental radiation exposure in relation to Canada's nuclear fuel waste management concept, AECL-9917.

NCRP (1991) Effects of ionizing radiation on aquatic organisms. National Council on Radiation Protection and Measurements, NCRP Report $\mathrm{N}^{\circ}$ 109, Bethesda, USA.

OSPAR (1998) Convention for the Protection of the Marine Environment of the North-East Atlantic, Sintra Statement, Ministerial Meeting of the OSPAR Commission, July 22-23, Sintra, Summary Record OSPAR 98/14/1, Annex 45.

Paquet F. (1993) Étude expérimentale des cinétiques de l'américium-24l chez le homard Hommarus gammarus. Analyse des mécanismes d'accumulation and de détoxification au niveau subcellulaire, Doctoral Thesis, Saclay, France.

Pentreath R.J. (1998) Radiological protection criteria for the natural environment, Rad. Protect. Dosim. $75(1-4), 175-179$.

Pentreath R.J. (1999) A system for radiological environmental protection: some initial thoughts and ideas, J. Radiol. Prot. 19 (2), 117-128.

Pentreath J., Lovett M.B. (1976) Occurrence of plutonium and americium in plaice from the NorthEastern Irish sea, Nature 262, 814-816.

Pentreath R.J., Woodhead D.S. (2000) A system for environmental protection: reference dose models for fauna and flora. In: 10th International Congress of the International Radiation Protection Association IRPA I0, "Harmonization of radiation, human life and the ecosystem". May 14-19, 2000, Hiroshima, Japan.

Polikarpov G.G. (1998) Conceptual model of responses of organisms, populations and ecosystems to all possible dose rates of ionising radiation in the environment, Rad. Protect. Dosim. 75 (1-4), 181-185.

Ribera D., Labrot F., Tisnerat G., Narbonne J.F. (1996) Uranium in the environment: occurrence, transfer, and biological effects, Rev. Environ. Contam. Toxicol. 146, 53-89.

Rose K.S.B. (1992) Lower limits of radiosensitivity in organisms, excluding man, J. Environ. Radioact. $15,113-133$.

Sazykina T.G. (1996) Effects of ionizing radiation on populations and ecosystems: theoretical approach and examples. In: International Symposium on Ionizing Radiation, B. Amiro, R. Avadhanula, G. Johansson, C.M. Larsson, M. Lüning (Eds.), Stockholm, Sweden, pp. 153-158.

Sparrow A.H., Underbrink A.G., Sparrow R.C. (1967) Chromosomes and cellular radiosensitivity. I The relationship of $\mathrm{D}_{0}$ to chromosome volume and complexity in seventy-nine different organisms, Radiat. Res. 32, 915-945.

Sugg D.W., Chesser R.K., Brooks J.A., Grasman B.T. (1995) The association of DNA damage to concentration of mercury and radiocesium in largemouth bass, Environm. Toxicol. Chem. 14, 6671-668.

Taskaev A.I., Frolova N.P., Popova O.N., Shevshenko V.A. (1992) The monitoring of herbaceous seeds in the 30-km zone of the Chernobyl nuclear accident, Sci. Tot. Environ. 112, 57-67.

Taub F.B. (1997) Unique information contributed by multispecies systems: examples from the standardized aquatic microcosm, Ecol. Applic. 7 (4), 1103-11 10. 


\section{IMPACT OF RADIOACTIVITY ON THE ENVIRONMENT}

Tsytsugina V.G. (1998) An indicator of radiation effects in natural populations of aquatic organisms, Rad. Protect. Dosim. 75 (1-4), 171-173.

UNSCEAR (1982) lonizing radiation: Sources and biological effects, United Nations Scientific Committee on the effects of atomic radiation, 1982 Report to the General Assembly, with Annexes, E.82.IX.8. United Nations, New York.

UNSCEAR (1996) Effects of radiation on the environment, United Nations Scientific Committee on the Effects of Atomic Radiation, 1982 Report to the General Assembly, Annex 1, United Nations, New York, 86 p.

Whicker F.W., Schultz V. (1982) Radioecology: Nuclear energy and the environment, Vol. II. CRC Press, Inc., Boca Raton, Florida.

Whicker F.W., Bedford J.S. (1995) Protection of the natural environment from jonizing radiation: Are specific criteria needed? In: Environmental impact of radioactive releases. International Atomic Energy Agency, IAEA-SM-339/193, Vienna, pp. 561-567.

Whicker F.W., Hinton T.G. (1996) Effects of ionising radiation on terrestrial ecosystems. In: International Symposium on Ionizing Radiation, B. Amiro, R. Avadhanula, G. Johansson, C.M. Larsson, M. Lüning (Eds.), Stockholm, Sweden, pp. 109-123.

Woodhead D.S. (1984) Contamination due to radioactive materials. In: Pollution and Protection of the Seas: Radioactive Materials, Heavy Metals and Oil, O. Kinne (Ed.), Vol. 5, Part 3, p. 1111. John Wiley and Sons, New York. 